\title{
First autochthonous malaria case due to Plasmodium vivax since eradication, Spain, October 2010
}

P Santa-Olalla Peralta (psantaolalla@msps.es)1, M C Vazquez-Torres' ${ }^{1}$, E Latorre-Fandós ${ }^{2}$, P Mairal-Claver ${ }^{3}$, P Cortina-Solano4,

A Puy-Azón 4 , B Adiego Sancho 5 , K Leitmeyer ${ }^{6}$, J Lucientes-Curdi7, M J Sierra-Moros ${ }^{1}$

1. Coordinating Centre for Health Alerts and Emergencies, Ministry of Health and Social Policy, Madrid, Spain

2. Haematology Department, Hospital San Jorge, Huesca, Spain

3. Microbiology Department, Hospital San Jorge, Huesca, Spain

4. Sub-directorate General of Public Health of Huesca, Regional Health Service of Aragón, Huesca, Spain

5. Service of Public Health Surveillance, Directorate General of Public Health of Aragón, Regional Health Service of Aragón, Zaragoza, Spain

6. European Centre for Disease Prevention and Control (ECDC), Stockholm, Sweden

7. Animal Pathology Department, Veterinary School, Universidad de Zaragoza, Zaragoza, Spain

Citation style for this article:

Santa-Olalla Peralta P, Vazquez-Torres MC, Latorre-Fandós E, Mairal-Claver P, Cortina-Solano P, Puy-Azón A, Adiego Sancho B, Leitmeyer K, Lucientes-Curdi J, Sierra-Moros MJ. First autochthonous malaria case due to Plasmodium vivax since eradication, Spain, October 2010. Euro Surveill. 2010;15(41):pii=19684 . Available online: http://www.eurosurveillance.org/ViewArticle.aspx?Articleld=19684

In October 2010, one case of autochthonous malaria due to Plasmodium vivax was diagnosed in Spain. The case occurred in Aragon, north-eastern Spain, where the vector Anopheles atroparvus is present. Although the source of infection could not be identified, this event highlights that sporadic autochthonous transmission of vector-borne diseases in continental Europe is possible and calls for enhanced surveillance and vector control measures.

\section{Background}

Malaria is a mosquito-borne parasitaemic disease caused by parasites of the Plasmodium genus and endemic in Africa, Asia, Central and South America. According to the World Health Organization (WHO), there were 247 million cases of malaria and nearly one million deaths worldwide in 2008 , mostly among children living in Africa [1]. Four species of Plasmodium have long been recognised to infect humans in nature: Plasmodium falciparum, $P$. vivax, $P$. malariae and $P$. ovale. Recently, the simian parasite $P$. knowlesi has been found as a cause of human malaria in some areas of south-east Asia [2]. Worldwide, P. falciparum and $P$. vivax are the most common causes of malaria. The malaria parasites are transmitted by female Anopheles mosquito vectors. Of the approximately 430 Anopheles species, only 20 species are important for transmission.

Infection with malaria parasites may result in a wide variety of symptoms, ranging from absent or very mild symptoms to severe disease and even death in the case of $P$. falciparum malaria. The main symptoms of malaria include episodes of cyclical or irregular fever, chills, headache, weakness, vomiting and diarrhoea. The incubation period in most cases varies from seven to thirty days after the infective mosquito bite.
In $P$. vivax malaria, the incubation period usually ranges from 10 to 21 days and sometimes up to a year. Unlike $P$. falciparum malaria, $P$. vivax malaria is rarely fatal. However, for $P$. vivax, clinical relapses may occur weeks to months after the first infection. These new episodes arise from dormant forms in the liver, and special treatment with primaquine - targeted at these liver stages - is mandatory for a complete cure.

\section{Situation in Europe and Spain}

Within the WHO European Region, six countries reported autochthonous malaria infections in 2008 caused by P. vivax: Azerbaijan, Georgia, Kyrgyzstan, Tajikistan (the only country in the Region reporting $P$. falciparum malaria), Turkey and Uzbekistan [3]. In the European Union (EU) and European Economic Area (EEA) countries, malaria has been eradicated since 1975 and nearly all reported malaria cases are imported. In 2008, 5,848 malaria cases were reported; the vast majority of cases for which the species was known were caused by $P$. falciparum (78\%) while less than $10 \%$ were caused by $P$. vivax [4]. During the last 10 years, less than 20 cases of autochthonous transmission of malaria have been reported in the EU/EEA $[3,5]$. Despite the presence of potential anopheline vectors in some countries, sustained local transmission has not been identified in continental EU countries [5].

In Spain, the last autochthonous case of malaria was reported in 1961 [6] and malaria was officially declared eradicated in 1964. According to the Spanish National Surveillance Network, an average of 400 imported malaria cases are reported each year (with less than $5 \%$ due to $P$. vivax). The Spanish population is susceptible to malaria infection given the absence or disappearance of the immunity acquired in the past by contact with the parasite. 
The principal potential anopheline vector of malaria in Spain is Anopheles atroparvus which is widely distributed throughout Spain (Figure) and can transmit Asiatic strains of $P$. vivax but is refractory to African strains of $P$. falciparum [7].

\section{Case report}

On 5 October 2010, the Regional Health Authorities of Aragon reported to the Coordinating Centre for Health Alerts and Emergencies at the Spanish Ministry of Health one laboratory-confirmed case of $P$. vivax malaria in a patient in their 40 s living in the province of Huesca (Region of Aragon). The patient had developed fever on 20 September 2010 and was diagnosed on 25 September with acute tonsillitis and started treatment with amoxicillin and ibuprofen. Four days later, the patient was hospitalised because of clinical deterioration with fever and jaundice. On the same day, Plasmodium spp. parasites were detected in the blood smear, and antimalarial treatment with chloroquine and primaquine was initiated. On 1 October the patient was dismissed in good clinical condition.

\section{Laboratory results}

Detection of macrocytosis on the first blood sample taken upon hospital admission led to a Giemsa staining where Plasmodium spp. parasites were unexpectedly identified. Further tests (Rapid Test Binax, chromatography) diagnosed Plasmodium spp. (non-falciparum). On 4 October, the National Centre for Microbiology in Madrid (National Reference Laboratory) confirmed the presence of $P$. vivax by microscopy and multiplex PCR. Genomic analysis of the parasite is still ongoing.

\section{Epidemiological investigation}

According to the epidemiological investigation, the patient did not have any travel history to an endemic/ epidemic area ever, or contact to persons visiting or

\section{FIGURE}

Distribution of Anopheles atroparvus in Spain (dots indicate presence)

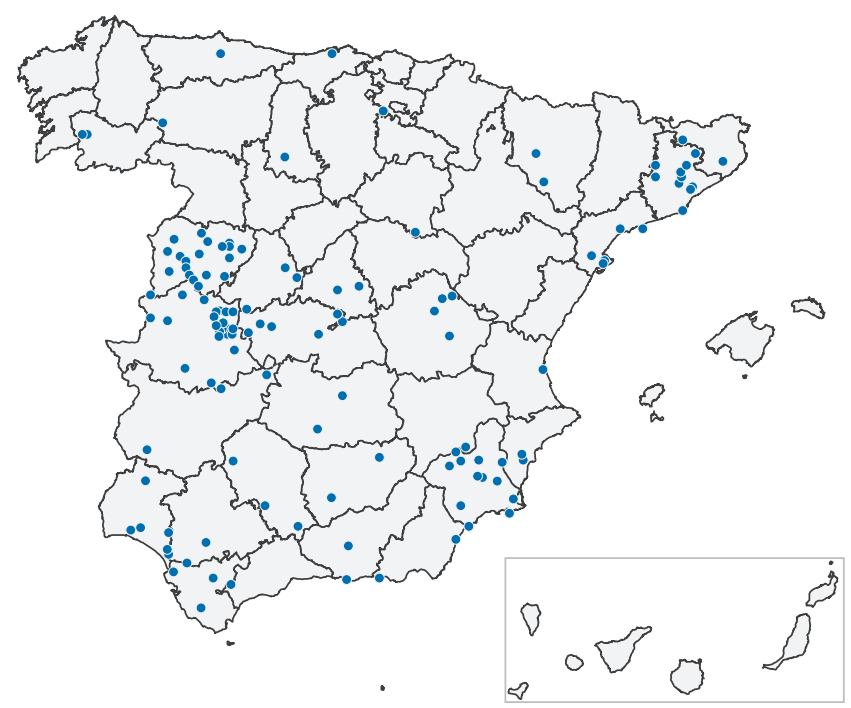

residing in such areas. There was no history of surgeries, invasive examinations or diagnostics, or blood transfusions. The patient never was an injecting drug user or had any treatments involving injections. The patient reported two visits to airports, Barcelona airport in summer 2008 and Zaragoza airport in summer 2009.

In the vicinity of the patient's residence there were swine exploitations and was frequently exposed to mosquito bites. Furthermore, the patient lives in an area of the province of Huesca where An. atroparvus is present in several nearby localities. No malaria cases have been reported amongst the case's contacts or residents in the locality. There have been no reports of imported malaria cases from this area in recent years, including 2010.

\section{Control measures}

The implemented control measures included testing household members for malaria, active case finding in the neighbourhood of the case and through alerting healthcare centres (including hospitals) in the area, as well as entomological survey and vector control. The entomological survey carried out so far has not proven the presence of Plasmodium parasites in local mosquitoes.

\section{Risk assessment for Spain}

Although the investigation was very detailed, we have not been able to identify the source of infection. Ongoing genetic analysis of the parasite may help to specify its possible origin. Transmission may have occurred through local Anopheles species after infection from people coming from endemic areas carrying gametocytes in their blood. Airport malaria caused by infected mosquitoes imported from endemic areas seems improbable due to the distance to the next international airport (approx. $100 \mathrm{~km}$ ) and the limited flight range of local anophelines $(4.5 \mathrm{~km})$.

The possibility of a secondary case originating from the reported case is unlikely as the patient has been treated, comprehensive control measures have been implemented, and the person had never donated blood.

In Spain, the situation following the eradication of malaria in 1964 is defined as anophelism without malaria' with the presence of potential vectors for the parasite (mainly An. atroparvus, which is a species refractory to $P$. falciparum) and environmental conditions favourable for the breeding, development and permanence of the vector [7]. The risk for local transmission of malaria will depend on the presence of parasitaemic individuals and competent vectors at a given time and place. This risk is reduced by early and appropriate detection and treatment of cases and vector control activities in place. However, it is still possible that other sporadic autochthonous cases could still be identified. 


\section{Conclusions}

Given the described conditions in Spain, an autochthonous case of malaria is not unexpected. Previous events, including the occurrence of several emerging vector-borne disease outbreaks in different countries in Europe, indicate that sporadic autochthonous transmission of vector-borne diseases in continental Europe is possible [9-11].

The available epidemiological information does not suggest that there is a risk for human health in the area. The epidemiological investigation suggested that this was a sporadic case with no evidence of further local transmission. With the current information, this event does not pose a significant risk to EU/EEA citizens. Despite the fact that autochthonous cases have been reported sporadically in the EU in the past, such cases never resulted in established local transmission involving more than a few cases.

Given the presence of competent vectors for malaria in the EU, we cannot exclude similar events in the future. Continued monitoring of the situation in areas where Anopheles mosquito populations are present is needed, including increased awareness among clinicians, to rapidly identify and report suspected malaria cases to respective authorities, and ensure an appropriate public health response.

\section{References}

1. World Health Organisation (WHO). Fact sheet No 94. April 2010 Malaria. Geneva: World Health Organization; 2010. Available from: http://www.who.int/mediacentre/factsheets/fso94/en/ index.html.

2. Luchavez J, Espino F, Curameng P, Espina R, Bell D, Chiodini $P$, et al. Human Infections with Plasmodium knowlesi, the Philippines. Emerg Infect Dis. 2008 May;14(5):811-3.

3. World Health Organisation (WHO), Regional Office for Europe. [Internet]. Centralized information system for infectious diseases (CISID) database. Malaria. Copenhagen: World Health Organization; 2010. Available from: http://data.euro.who.int/ cisid/

4. European Centre for Disease Prevention and Control (ECDC). The European Surveillance System (TESSy). TESSy database. Data source 2008. Stockholm: World Health Organisation; 2010.

5. Alten B, Kampen $\mathrm{CH}$, Fontenille D, eds. Malaria in Southern Europe: resurgence from the past? Emerging Pests and Vector-Borne Diseases in Europe, ed. W. Takken and B. Knols. 2007, Wageningen Academic Publishers, Wageningen, The Netherlands. $35-58$

6. Clavero G. [The eradication of malaria in Spain]. Rev San Hig Publ. 1961. 35: p. 265-92. Spanish.

7. Bueno Marí R, Jiménez Peydró R. [Malaria in Spain: entomological aspects and future outlook]. Rev Esp Salud Pública. 2008;82(5):467-79. Spanish.

8. Delacour S, Melero-Alcibar R, Aranda C, Cortés M, Eritja R, Escosa $R$ et al. Detailed maps of the geographical distribution of the mosquitoes of Spain based on a literature review. Part II: Genus Anopheles. The 5th European Mosquito Control Association Workshop. Turin Italy (2009).

9. Schmidt-Chanasit J, Haditsch M, Schöneberg I, Günther S, Stark K, Frank C. Dengue virus infection in a traveller returning from Croatia to Germany. Euro Surveill. 2010;15(40):pii=19677. Available from: http://www.eurosurveillance.org/ViewArticle. aspx?Articleld =19677

10. La Ruche G, Souarès $Y$, Armengaud A, Peloux-Petiot F, Delaunay $P$, Desprès $P$, et al. First two autochthonous dengue virus infections in metropolitan France, September 2010. Euro Surveill. 2010;15(39):pii=19676. Available from: http://www. eurosurveillance.org/ViewArticle.aspx?Articleld=19676
11. Institut de Veille Sanitaire (InVS, French Institute for Public Health Surveillance). [Autochtnous cases of chikungunya infection in the Var] 27 September 2010. Available from: http:// www.invs.sante.fr/regions/sud/pe_paca_corse_011010.pdf 